\title{
Outbreak of rotavirus gastroenteritis in a nursing home, Slovenia, December 2010
}

A Trop Skaza (alenka.skaza@zzv-ce.si) ${ }^{1}$, L Beskovnik ${ }^{1}$, T Zohar Cretnik $^{1}$

1. Institute of Public Health Celje, Celje, Slovenia

Citation style for this article:

Trop Skaza A, Beskovnik L, Zohar Cretnik T. Outbreak of rotavirus gastroenteritis in a nursing home, Slovenia, December 2010. Euro Surveill. 2011;16(14):pii=19837. Available online: http://www.eurosurveillance.org/ViewArticle.aspx?Articleld=19837

A gastroenteritis outbreak affected 45 people (40 residents and five staff) in a nursing home for the elderly in the Celje region, north-east Slovenia, between 17 December and 31 December 2010. Rotavirus group A was laboratory confirmed in the stools of five ill individuals. The outbreak was identified when the number of affected persons was high but was successfully controlled after implementing preventive measures.

\section{Background}

On 28 December 2010, the regional epidemiologist of the Institute of Public Health Celje, North East Slovenia, was informed that several residents and staff of a nursing home in the Celje region had symptoms of acute gastroenteritis. Symptoms had first occurred in two residents on 17 December. On 26 December, an 88 year-old resident had been hospitalised for dehydration because of diarrhoea and vomiting. By 28 December, 32 people (four staff and 28 residents) were reporting one or a combination of symptoms including diarrhoea, vomiting, malaise and in four cases elevated body temperature. On 28 December, the Department of Medical Microbiology, Institute of Public Health, Celje confirmed the presence of rotavirus group A antigens in the 88 year-old resident's stool.

Rotavirus infections are well documented in preschool children and present a problem in developed and developing countries alike. Worldwide, 870,000 children under five years old die from rotavirus infections every year $[1,2]$. In adults, symptomatic rotavirus infections are relatively rare, but can cause health problems and outbreaks in the elderly and in immunocompromised individuals $[3,4]$. For children under five, there are two licensed vaccines against rotavirus infections.

Rotaviruses are RNA viruses from the Reoviridae family; they are divided into seven serogroups (A to $G$ ) on the basis of antigen groups. Infections in humans are caused by serogroups A, B and C, serogroup A being the most common.

\section{Outbreak investigation}

On 28 December, an outbreak investigation was initiated. The nursing home for the elderly comprised
121 residents aged from 66 to 95 years, 85 females and 36 males. The residents were cared for by 30 of a total 62 staff which also included 14 kitchen staff and 18 support personnel (cleaners, drivers and janitor). Of the residents, 66 were fully mobile, 26 were wheelchair users and 29 were bed-bound. The rooms for residents are either equipped with one or two beds and are located in the basement, on the ground floor, at the first level, and in two lofts. In addition, there are four small kitchens on each respective floor, a dining hall and a living room. The nursing home does not have a separate unit for bed-bound residents. Mobile residents can go about freely in and around the nursing home.

Enterovirus infection was suspected based on the microbiological confirmation of rotavirus gastroenteritis in the hospitalised resident. Every resident and staff member (epidemiological link) who presented with at least one of the following symptoms and signs from 17 December was classified as a probable case: diarrhoea (three loose stools/day), vomiting and elevated body temperature $\left(37^{\circ} \mathrm{C}\right)$. A confirmed case was considered as a case with clinical symptoms and laboratory confirmation.

A total of 151 epidemiological questionnaires were distributed to all residents and nursing staff with questions on the date of onset of symptoms if any, gastroenteritis-related health problems and their duration, treatments, and ingestion of food and beverages outside the nursing home. The residents were also asked to identify the room they occupied, and the nursing staff reported which residents they cared for and possible onset of symptoms of gastroenteritis in their family members, if applicable. In parallel, information on measures to prevent the spread of the disease and instructions on how and what samples to collect (vomit, stool) for microbiological analysis were distributed [5].

We received completed questionnaires for all nursing staff and all residents by 4 January 2011. Residents from all building levels of the nursing home felt ill; no level-based clustering was observed. All the staff affected had provided nursing care to symptomatic 
residents. According to the probable case criteria, the two residents who became ill on 17 December 2010 (11 days before we were informed of the outbreak) were identified as the first two cases in the outbreak. Between 28 and 30 December, 15 residents became ill, and no further cases were identified after 31 December (Figure). A total of five of 30 nursing staff (16.7\%), and 40 of 121 residents (33\%) became ill during the outbreak. The overall attack rate was 30\%. Only one resident was hospitalised. None of the kitchen staff and support personnel became ill as they were informed about the outbreak and asked to report if they had any symptoms. The staff did not report any symptoms of gastroenteritis in their family members.

Diarrhoea was reported by all 45 affected individuals, 19 experienced vomiting and four had elevated body temperature. Some patients also reported abdominal pain (Table). The median age of the affected staff was 35 years (mean: 35 years, age range: 23 to 44 years), the median age of the affected residents was 78 years (mean: 82.4 years, age range: 66 to 95 years). The average duration of symptoms of gastroenteritis was $\mathbf{2 . 4}$ days (from one to four days) in staff, and three days in residents (one to nine days). The outbreak affected 26 women and 19 men. The highest proportion of resident cases was among fully mobile residents (29 of 40 cases), followed by bed-bound residents (seven of 40 cases) and residents on wheelchairs (four of 40 cases).

\section{Laboratory investigation}

One stool sample was collected from the 88 year-old hospitalised resident on 26 December and was sent to the Department of Medical Microbiology, Institute of Public Health Celje. On 28 December, results of enzyme-linked immunosorbent assay (ELISA) testing for antigens of adenoviruses, astroviruses and group A rotaviruses were available. Routine diagnostic procedures for rotavirus infections usually include spectrophotometric enzyme immunoassay (EIA), which is highly sensitive and detects group A rotaviruses only. Qualitative EIA was used to confirm antigens of group A rotaviruses (ProSpectTM Rotavirus Microplate Assay, OXOID). Up to 28 December, cultures for Salmonella spp., Shigella spp., Campylobacter spp. Yersinia spp., Clostridium difficile toxin $\mathrm{A}$ and $\mathrm{B}$, and $\mathrm{C}$. difficile did not point to infection with these bacteria and were confirmed to be negative on 30 December.

On 28 and 29 December, taking in consideration the result of the hospitalised patient, five additional stool samples from four symptomatic residents and one staff member were tested only for the presence of antigens of astroviruses, adenoviruses and group A rotaviruses. EIA was used to confirm rotavirus group $A$ antigens in four samples, including three from the residents and one from the staff; one sample was negative. All individuals tested were negative for noroviruses.

\section{Control measures}

On 30 December, following the confirmation of a rotavirus outbreak, a special sanitary inspection of the

\section{FIGURE}

Epidemic curve for cases of rotavirus gastroenteritis in a nursing home for the elderly, Slovenia, December 2010 ( $\mathrm{n}=45$ )

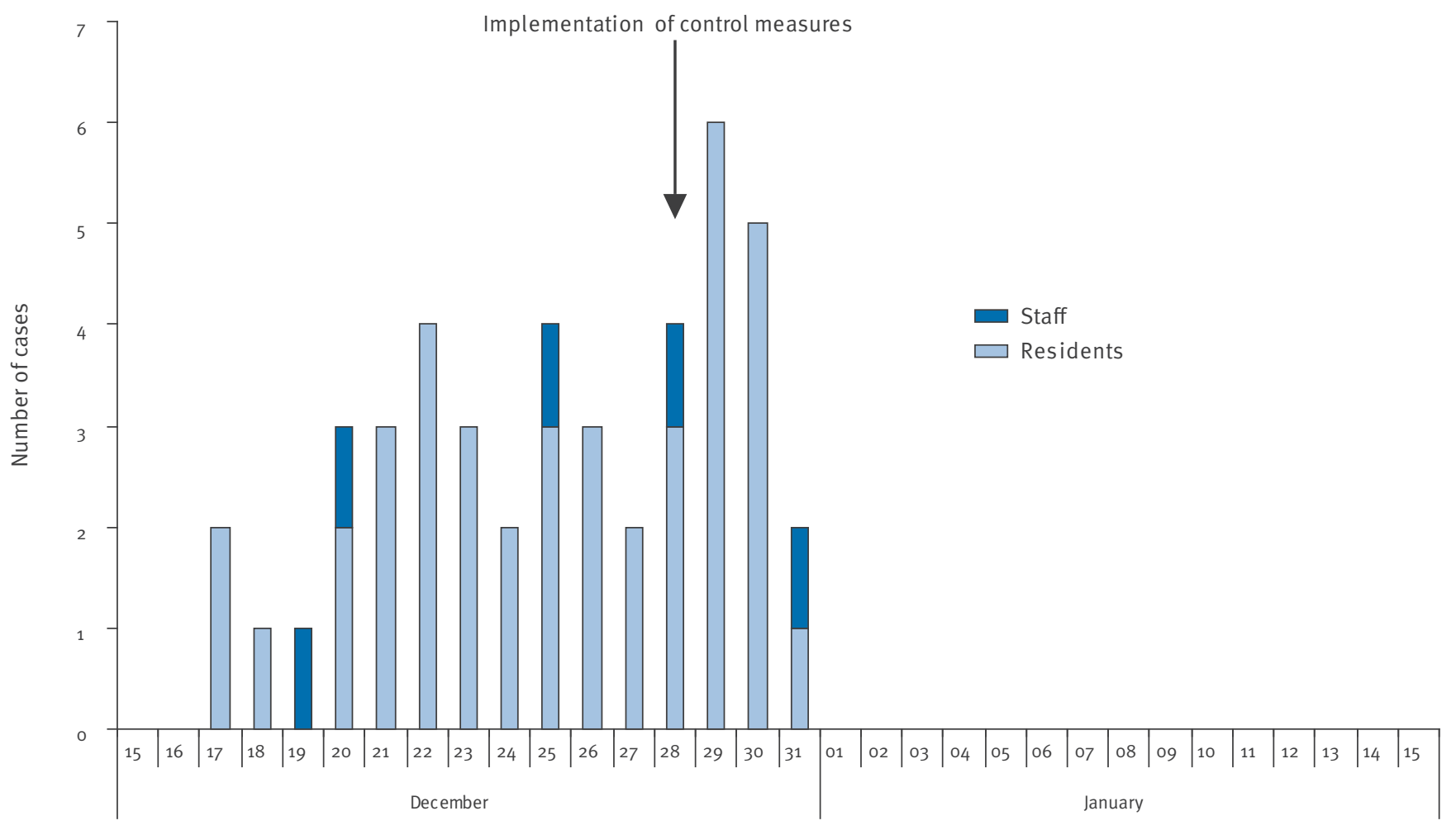

Date of onset 
nursing home was performed. Measures to prevent the spread of viral diarrhoea were put in place; strict hand hygiene and cleaning with an appropriate disinfectant for viruses, cleaning and disinfection of equipment, surfaces and rooms. Regular airing of premises was recommended. Sanitary inspection of proper disposal of incontinence pads with excrements from residents was conducted. As a temporary measure, contacts between the affected and non-affected residents were limited; cohort isolation of the affected was not implemented. The affected staff were removed from work for a period of one to four days until they did not present any more symptoms $[6,7]$.

\section{Discussion}

We describe an outbreak of rotavirus gastroenteritis in a nursing home for the elderly. On 17 December, two residents became ill at the same time; the first resident was bed-bound and the second was mobile and visiting the first one. The first member of the staff fell ill on 19 December (Figure). The outbreak, affected 40 of 121 residents and five of 30 nursing staff. All five affected members of the staff had provided nursing care to bedbound residents. The most frequent symptoms were diarrhoea, vomiting and elevated body temperature. The average duration of illness was different for staff and residents, 2.4 and three days, respectively. All affected persons made full recovery; only one resident was hospitalised.

Rotavirus gastroenteritis symptoms usually accompany primary infection in childhood, which is followed by protection against subsequent symptomatic infection. For this reason, the ratio of symptomatic to asymptomatic infection decreases with age. In prospective studies, symptomatic infection rates were highest in children under two years, and lowest in those of 45 years of age [3]. Rotavirus infection in immunocompromised adults can have a variable course from asymptomatic to severe and sustained infection [4]. Vaccination for infants from six to 26 weeks of age, which has already been included in some national vaccination programmes, will serve to decrease the burden of rotavirus infections in the future [8,9]. In Slovenia, rotavirus vaccination for infants is available against payment [10].

\section{TABLE}

Clinical manifestation in ill individuals, rotavirus gastroenteritis outbreak, Slovenia, December $2010(n=45)$

\begin{tabular}{|l|c|}
\hline Clinical manifestation & Number of individuals ${ }^{\text {a }}$ \\
\hline Diarrhoea & 45 \\
\hline Vomiting & 19 \\
\hline Elevated temperature & 4 \\
\hline Stomach pains & 1 \\
\hline Feeling unwell & 3 \\
\hline Malaise & 12 \\
\hline
\end{tabular}

a Each individual could record up to six symptoms listed.
Before 2008, rotavirus gastroenteritis outbreaks in Slovenia were reported mostly in preschool and school environments [11]. In 2008, however, rotavirus gastroenteritis outbreaks in nursing homes for the elderly in Slovenia were first recorded in addition to norovirus infections [12]

Our investigation shows another outbreak of rotavirus gastroenteritis in an elderly nursing home, highlighting the potential of rotavirus outbreaks in such a setting. Our results are in agreement with other studies reporting that long-term residence in a closed community is a risk for rotavirus illness [13]. Noteworthy in our investigation, is that five of 30 younger nursing staff (ranging from 23 to 44 years) were affected. This indicates that rotavirus infections can occur in all age groups and affect caretakers of an elderly home, who in turn can contribute to the spread of the disease. This is not entirely unexpected as faeces and vomit from infected individuals can contain more than $10^{13}$ infectious infectious particles* per gram and only 10 to 100 of these are required to transmit infection [5]. Future epidemiological studies are needed to assess the impact of rotavirus infections in the elderly.

To this effect, outbreaks need to be not only registered, but also reported as close as possible to onset, so that microbiological diagnostic and complete monitoring can be implemented as fast as possible. In the present outbreak, public health authorities were only notified once the number of affected persons was high. This situation is likely to occur frequently because of the speed at which rotavirus gastroenteritis outbreaks can spread, so our investigation highlights the importance of a tight collaboration and dialogue between nursing home staff and public health authorities. More efforts need to be focused on increasing vigilance among caretakers for elderly or vulnerable groups and training caretakers to communicate outbreaks in a timely manner. This will prevent delays in putting in place containment measures and will allow for better care of vulnerable groups such as the elderly or immunocompromised patients.

*Erratum: The number $10^{13}$ was corrected on 09 April 2011.

References

1. Van Damme P, Giaquinto C, Huet F, Gothefors L, Maxwell M, Wielen $M$, et al. Multicentre prospective study of the burden of rotavirus acute gastroenteritis in Europe, 2004-2005: The REVEAL Study. J Infect Dis. 2007; 195 Suppl 1:S4-S16.

2. Parashar UD, Gibson CJ, Bresse JS, Glass RI. Rotavirus and severe childhood diarrhea. Emerg Infect Dis. 2006;12(2):304-6.

3. Anderson EJ, Weber SG. Rotavirus infection in adults. Lancet Infect Dis. 2004;4(2):91-9.

4. Kirk MD, Fullerton KE, Hall GV, Gregory J, Stafford R, Veitch $M G$, et al. Surveillance for outbreaks of gastroenteritis in long-term care facilities, Australia, 2002-2008. Clin Infect Dis. 2010;51(8):907-14. 
5. Guardado JA, Clara WA, Turcios RM, Fuentes RA, Valencia D, Sandoval R, et al. Rotavirus in El Salvador: an outbreak, surveillance and estimates of disease burden, 2000-2002. Pediatr Infect Dis J. 2004;23(10 Suppl):S156-60.

6. Kroneman A, Vennema H, van Duijnhoven Y, Duizer

E, Koopmans M. High number of norovirus outbreaks associated with a GGII.4 variant in the Netherlands and elsewhere: does this herald a worldwide increase?. Euro Surveill. 2004;8(52):pii=2606. Available from: http://www. eurosurveillance.org/ViewArticle. aspx?Articleld=2606

7. Barker J, Vipond IB, Bloomfield SF. Effects of cleaning and disinfection in reducing the spread of Norovirus contamination via environmental surfaces. J Hosp Infect. 2004;58(1):42-9.

8. Kudjawu Y, Lévy-Bruhl D, Pastore Celentano L, O’Flanagan D, Salmaso S, Lopalco PL, et al. The current status of HPV and rotavirus vaccines in national immunisation schedules in the EU - preliminary results of a VENICE survey. Euro Surveill. 2007;12(17):pii=3181. Available from: http://www. eurosurveillance.org/ViewArticle.aspx? Articleld=3181

9. Macartney KK, Porwal M, Dalton D, Cripps T, Maldigri T, Isaacs D, et al. Decline in rotavirus hospitalisations following introduction of Australia's national rotavirus immunisation programme. J Paediatr Child Health. 2011;47:1440-5.

10. The Slovenian immunoprophylaxis and chemoprophylaxis programme in 2009. Official Gazette of RS No. 24/09. Slovenian.

11. Institute of Public Health of the Republic of Slovenia. [Epidemiological surveillance of reported communicable diseases in Slovenia 2009]: Ljubljana: Ministry of Health of the Republic of Slovenia and Institute of Public Health of the Republic of Slovenia; Sep 2010. Slovenian. Available from: http://www.ivz.si $/ ? \mathrm{ni}=105 \& \mathrm{pi}=5 \&$ 5 Filename $=2491$. pdf\&_5_Mediald=2491\&_5_AutoResize=false \&pl=105-5.3.

12. Grmek Kosnik I, Peternelj B, Pohar M, Kraigher A. Outbreak of norovirus infection in a nursing home in northern Slovenia, July 2007. Euro Surveill. 2007;12(41):pii=3286. Available from: http://www.eurosurveillance.org/ViewArticle. aspx?Articleld $=3286$

13. Iijima Y, Iwamoto T, Nukuzuma S, Ohishi H, Hayashi K, Kobayashi N. An outbreak of rotavirus infection among adults in an institution for rehabilitation: long-term residence in a closed community as a risk factor for rotavirus illness. Scand I Infect Dis. 2006;38(6-7):490-6. 